\title{
DRINK IN RELATION TO THE POOR LAW.
}

\author{
BY ROBERT WAITE, J.P. \\ Birmingham Board of Guardians, Chairman of Assessment and \\ Children's Homes Committees.
}

WHETHER the evils of the drink habit are the cause of defective social conditions, or whether the drink habit springs from the misery of some forms of our industrial life, is not pertinent to our inquiry. The baneful influence of drink cannot be gainsaid, and the present duty is to try to discover if and how it influences the working and the cost of the English Poor Law. Illustrating this attitude of doubt or of openmindedness, it may be useful to refer to the Floodgate Street area-a district of Birmingham that a few years ago embodied all the evils and difficulties of a city slum. The area contained 114 acres occupied by dwelling houses, manufactories and warehouses, railways and canals. The atmosphere was smoky and practically sunless. The population was nearly 10,000 -about 86 to the acre. There were more licensed houses in proportion to the population than in any other part of Birmingham. The average death-rate for the five years $1899-1903$ was $31^{\circ} 6$ per 1,000 , against a death-rate for the whole city (including this area) of $19 \cdot 38$. The mortality was 60 per cent. higher than the city as a whole. Out of the whole number of deaths, viz., 1559, there died in the workhouse 315 , to say nothing of those which occurred in prison, asylums, or hospitals. The death-rate from measles, tuberculosis, premature birth, and accident was twice that of the city ; and for bronchitis, pneumonia, and pleurisy nearly three times. Alcoholism and cirrhosis of the liver showed a death-rate of 0.44 per 1,000 as compared with 0.19 in other and more temperate wards. This district made the heaviest calls upon the Poor Law, as well as on the voluntary philanthropic agencies of the city. 


\section{The British Journal of Inebriety}

Dr. Robertson, the Medical Officer of Health for Birmingham, in concluding his Report for 1904, makes the following observation: "It is difficult to say whether drink, combined with ignorance and carelessness, does not play as important a part-or even a more important part-than all the conditions of bad housing, smoky atmosphere, and poverty. One cannot but be struck, in going over such an area in the evening, with the number of public houses, and with the extent to which they are used as clubs. A large number of men and women in the area soak themselves with drink every day, thereby ruining their constitutions, bringing on poverty, and indirectly causing most unhealthy conditions. Bearing in mind such conditions resulting from the excessive use of drink, the drink question has a public health aspect of the greatest importance."

The Report of the Royal Commission on the Poor Laws and the Relief of Distress is the most authoritative statement of our time. Its findings are beyond all question. The following paragraphs are transcribed in an abbreviated form: "A great weight of evidence indicates drink as the most potent and universal factor in bringing about pauperism. Some witnesses also indicate gambling as a serious and growing cause, but gambling, though it wastes the resources of its victims, does not lead to such physical and moral degeneration as drink." Again, "The more that one inquires into the history of workhouse inmates, the more one is struck with the fact that drinking is one of the chief causes of pauperism." I also extract the following from my own evidence before the Commission: "Apart from accident, the ordinary illnesses of life, and bereavement, the root cause of pauperism and lunacy is drink. During his six years' experience the writer has never been present on any occasion when an application for in or outdoor relief has been heard emanating from any applicant who has been a recognized abstainer from alcoholic drinks. On a recent occasion, when the workhouse inmates were gathered, this statement was made in the presence of 400 inmates of the workhouse, and inquiry was pressed as to whether in any individual case it was an untrue statement. There was no denial or dissent." A striking confirmation of this experience is given in the evidence of $\mathrm{Sir}$ James S. Davy, C.B. : "You will find, I think, also, that practically no total abstainer is ever a pauper. Stated like that, I think there is a certain amount of cant about it. The reason why a man who is an abstainer does not become a pauper is not 
because he is a teetotaler, but because he has got sufficient moral courage and strength to submit to a present deprivation for some future good."

The series of special reports found in Vol. XIII. of the Appendix to the Report also affords very material evidence as to the widespread infiuence of drink and intemperance. The General Summary of the inquisition is thus stated: "The reports show that drink is by far the most general cause of poverty. Waste of money on drink, even when unaccompanied by drunkenness, is said to be the cause of poverty. In every diocese, and in almost every parish where poverty exists, drink is mentioned as the cause. Intemperance among women is frequently mentioned."

With regard to infantile mortality, some quotations from $\mathrm{Dr}$. Hope, the Medical Officer for Liverpool, may be useful : " When we find, for example, that in 874 families, taken consecutively on account of the fact that in each the death of an infant had occurred, the total number of infants born in those families had been 3,801 , and that no less than 1,895 of them had perished, practically all in infancy-representing an infant mortality of 498 per thousand -it is obvious that we must go further into the question of the personal element. Unfortunately, long series of cases of this description are recorded, in which obvious drunkenness in an extreme degree is the pre-eminent feature associated with the loss of the infant, the money wasted, the parents drink-sodden, and every feature of intelligent attention to the infant wanting. With these there comes the long string of examples in which the alternations between the gaol and the workhouse are factors, which make it abundantly plain that the children of the family have had no proper maternal solicitude bestowed upon them, and have perished in consequence. "It is desirable to add a few words in reference to the Jewish community, and for the purpose of illustration to take fifty poor-some very poor-Jewish families, taken consecutively. The family earnings averaged from $10 \mathrm{~s}$. to 30s. per week. The points which stand out are, first, that in every instance the children are well looked after, all suitably clad, and not one ragged or bare-footed child seen. . . . Thriftiness and sobriety were universal ; no drunkenness at all."

A further extract from Dr. Robertson's Birmingham report emphasizes the same fact. He says: "It is scarcely necessary to point out that much of the poverty is due to drink, and, there- 
fore, that any reform which has for its object the reduction of this evil must be welcomed by all who are anxious to reduce the heavy infant mortality which occurs among the children of those who spend money in drink which should go to purchase necessaries for their children."

Any unnecessary loss of infant life obviously tends to the impoverishment of the nation, and the recorded statistics that twice as many children are suffocated by overlying on the night between Saturday and Sunday than on any other, points to one influence, and one influence only.

Another point of contact between the drink evil and the Poor Law is seen in the infirmaries of our large towns. Anyone who has shared in the management of these institutions must recognize the very considerable proportion of patients whose condition is due to or aggravated by alcoholic indulgence. The late Dr. Jordan Lloyd of Birmingham is thus reported in the Licensed Trade News of October 10, 1903 : "The majority of the hundreds of patients in his wards at the workhouse infirmary admitted that at one time or another of their lives they had drunk too freely." And Dr. Andrew Clark, Senior Physician at the London Hospital, said: "As I looked at the hospital wards to-day, and saw that seven out of ten owed their disease to alcohol, I could not but lament that the teaching about this question was not more direct."

Finally, under this head Sir Victor Horsley has given this dictum : "A large number of diseases are constantly induced by alcohol. In many, alcohol plays the part of the finally determining cause."

Speaking from my own personal experience as Chairman of the Children's Home Committee for the last two years, I cannot avoid the conclusion that drink is the predominant cause in depriving children of their parents' loving care. A very large proportion of the cases are statutory adoptions, a precaution rendered necessary to prevent the ruin of child life by drunken and immoral parents or friends. In many other instances action by the N.S.P.C.C. has been the determining cause of children coming under the Poor Law. The Director of this Society said in 1908 : "Where children are cruelly neglected there is, in 90 per cent. of the cases, a history of habitual intemperance in one or both parents"; while Dr. Barnardo is responsible for the statement that " 85 per cent. of his charges came into his hands either directly or indirectly through drink." Can it be doubted that the suffering in the main falls on the child? 